\title{
Identification of the Procedural Accidents During Root Canal Preparation Using Digital Intraoral Radiography and Cone Beam Computed Tomography
}

\author{
K.-Ivácson A.-Csinszka1', Monea Adriana Maria ${ }^{1}$, Monea Monica1, Pop Mihai ${ }^{1}$, Borda Angela² \\ 1 Discipline of Odontology and Oral Pathology, Faculty of Dental Medicine, UMF Tirgu-Mures \\ 2 Discipline of Histology, Faculty of Medicine, UMF Tirgu-Mures
}

Crown or root perforation, ledge formation, fractured instruments and perforation of the roots are the most important accidents which appear during endodontic therapy.Our objective was to evaluate the value of digital intraoral periapical radiographs compared to cone beam computed tomography images (CBCT) used to diagnose some procedural accidents. Material and methods:Eleven extracted molars were used in this study. A total of 18 perforations and 13 ledges were created artifically and 10 instruments were fractured in the root canals. Digital intraoral periapical radiographs from two angles and CBCT scans were made with the teeth fixed in position. The images were evaluated and the number of detected accidents were stated in percentages. Statistical analysis was performed using the chi square-test. Results:On digital periapical radiographs the evaluators identified 12 (66.66\%) perforations, 10 (100\%) separated instruments and 10 (76.9\%) created ledges. The CBCT scans made possible the recognition of 17 (94.66 \%) perforations, 9 (90\%) separated instruments and 13 (100\%) ledges. The totally recognized accidental procedures showed significant differences between the two groups. $(p<0.05)$ Conclusion: Digital periapical radiographs are the most common imaging modalities used during endodontic treatments. Though, the CBCT allows a better identification of the procedural accidents.

Keywords: endodontics, procedural accidents, digital radiography, $\mathrm{CBCT}$

Received: 22 November 2016 / Accepted: 07 June 2016

\section{Introduction}

During root canal treatment a practitioner confronts with unwanted and unforeseen challenges which can affect the prognosis of the tooth. There are many such procedural accidents, which can be classified depending on the stage of the root canal therapy when they are caused. Swallowed instruments, crown or root perforation during access cavity preparation, ledge formation, separated instruments, perforation of the root canals during preparation of the canals are the most important accidents a dentist should try to avoid, to recognize and treat.[1]

Various techniques and instruments such as electronic apex locators, operative microscopes or endoscopes have been suggested for detection of the mentioned accidents which appear during cleaning and shaping, but none of these turned out to be the best diagnostic method.

Radiographic examination (X-ray)- intraoral periapical radiographs- are the most accepted and widely used imaging modalities in endodontics [1]. This diagnostic method has its inherent limitations as it reflects a two-dimensional (2D) projection of a three-dimensional structures (alveolar bone and teeth), which causes geometric distortion of the elements and restricts the information about the size, extension, and location of the root and periapical lesions $[2,3]$.
The introduction of the computer tomography in dentistry was a big step forward in endodontics. The captured images are three dimensional (3D) and offer exact information about the details of the hard and soft tissues [4-6].

Early and correct diagnosis of the procedural accidents is important to determine the best treatment plan as soon as possible.

The aim of this in vitro study was to evaluate the value of digital intraoral periapical radiographs (2D) compared to cone beam computed tomography images (CBCT, 3D) used to diagnose some procedural accidents- perforations, blocked instruments and ledges- which appear during root canal therapy.

\section{Material and methods}

Eleven extracted intact superior and inferior molars with different curvatures of the roots were used in this study. Teeth with evidence of previous endodontic treatment were excluded.After access cavity preparation with diamond burs, the coronal pulp was removed using a globular bur. Patency of the root canals was established with a size $10 \mathrm{~K}$ - file (DentsplyMaillefer) and 2,5\% sodium hypochlorite was used as irrigant.

Procedural accidents were induced on the curved roots.

Coronal and interradicular perforations were made using diamond globular burs. Root perforations in the coro- 
nal third of the roots were made with Gates- Glidden burs, rotary root canal preparation instruments and hand files.

To perforate the middle and the apical third of the roots rotary instruments and hand files were forced into the root canals until the perforation was obtained.

In narrow root canals, after penetration with a size 10 K-file, larger files- size 40 and 50- were forced in the canal to obtain artificial ledges.

Size 15 and 20 K-files were introduced into the root canals and forced to separate in order to simulate root canals containing fractured instruments.

A total of 18 perforations and 13 ledges were created artificially and 10 instruments were fracturedin the root canals.

Teeth were fixed in position using a putty impression material (Zetaplus, Zermack). Digital intraoral periapical radiographs were made using X-Mind AC (Satelec) from two angles: mesiodistal and buccopalatal/lingual. (Figure 1 and Figure 2)

CBCT scans were made with Cranex 3Dx (Soredex). Eleven teeth were fixed in the impression material next to each other as a simulation of a human mandible. (Figure 3)

The radiographs and the CBCT scans were evaluated by 2 endodontists. It was allowed to the evaluators to adjust brightness, contrast and magnification of the captured images for obtaining the best visual results. Only those procedural accidents were included which were recognized by both doctors doubtlessness. The induced accidents, which were recognized only by one evaluator or the doctors weren't sure on their decision were excluded.

The in vitro caused procedural accidents were identified and the two methods were compared. The number of the detected accidents was compared to the total number of the triggered accidents and was stated in percentages in order to establish the sensitivity of the two imaging techniques that were used (X-ray and CBCT).

Statistical analysis was performed using the chi squaretest to compare the sensitivity of the digital radiography with the computer tomography images. The results were considered significant at a value of $\mathrm{p}<0.05$.

\section{Results}

The careful examination of the teeth with the two imaging techniques- digital periapical radiographs and CBCT- revealed the following results:

\section{Perforations:}

To identify the perforations the radiographs were evaluated from two incidences, mesiodistal and buccopalatal/lingual. Only $12(66.66 \%)$ of the total of 18 perforations were recognized by both evaluators (Figure 4).

Using the CBCT scans $17(94.44 \%)$ out of the 18 artificially created perforations could easily be detected (Figure 4).

Statistical analysis showed significant differences $(\mathrm{p}<0.05)$ between the two imaging techniques (Table IA).

\section{Fractured instruments:}

On digital periapical radiographs all 10 (100\%) broken instruments in the root canals were identified (Figure 4).

The CBCT scans made possible the recognition of 9 (90\%) fractured instruments (Figure 4).

These results showed no statistically significant differences between the two techniques while evaluating the fractured instruments in the root's canals (Table IB).

\section{Ledges:}

Using the digital radiographs from two different incidences, 10 of 13 created ledges (76.9\%) were recognized (Figure 4).

CBCT scans made possible the identification of the ledges in $100 \%$ of the cases (Figure 4).

Statistical analysis showed no significant differences between the two techniques when evaluating the triggered ledges (Table IC).

The totally recognized accidental procedures by using the digital periapical radiography and the CBCT scans

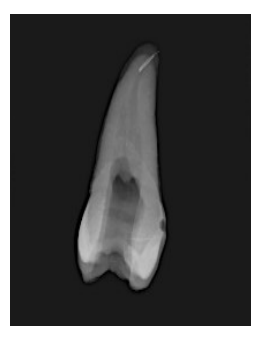

Fig. 1. Digital radiograph in mesiodistal wiew.

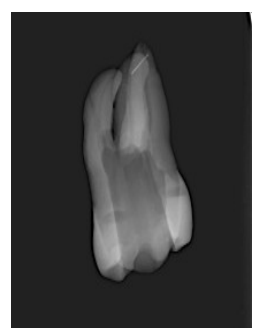

Fig. 2. Digital radiograph of the same tooth in buccopalatal wiew.

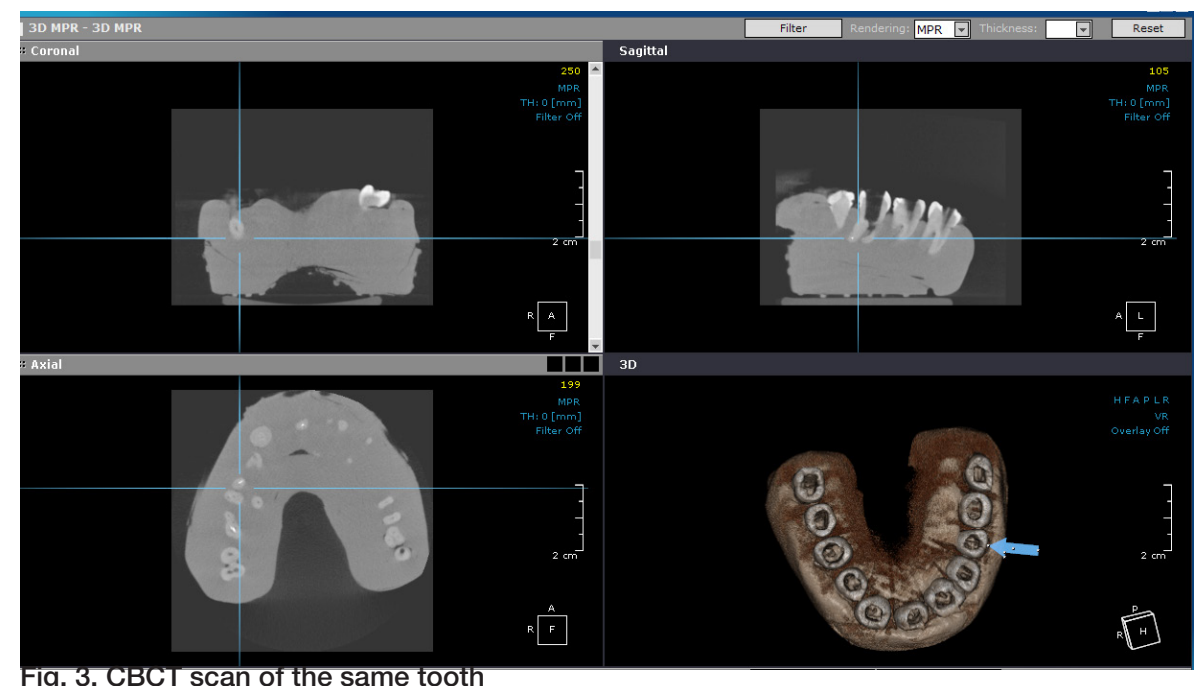

FIg. 3. CBCI scan of the same tooth 


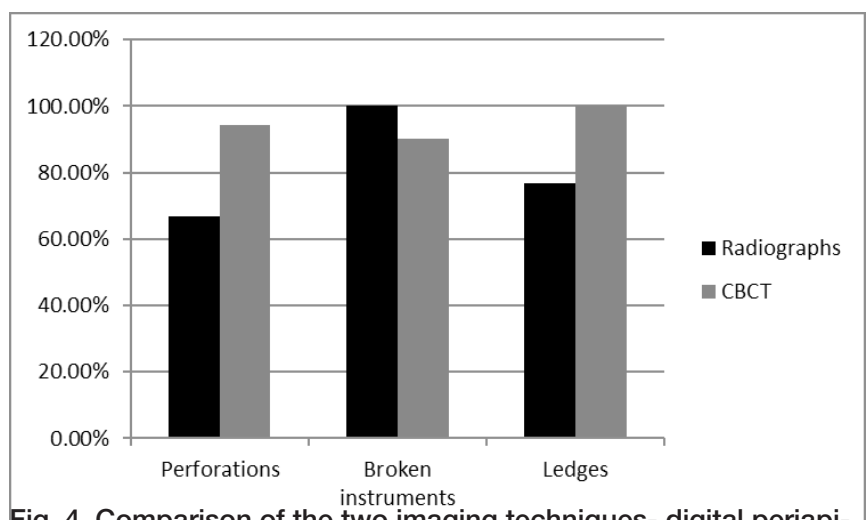

Fig. 4. Comparison of the two imaging techniques- digital periapical radiographs and CBCT scans-the recognition of the different procedural accidents stated in percentages.

showed significant differences between the two study groups $(\mathrm{p}<0.005)$ (Table ID).

\section{Discussion}

Procedural accidents during root canal preparations appear frequently. To increase the prognosis of the involved tooth,

Tab. I. Statistical analysis of the recognized and unrecognized procedural accidents on radiographs and CBCT scan. A. perforations B. broken instruments $C$. ledges $D$. all accidents

A

\begin{tabular}{lccc}
\hline & $\begin{array}{c}\text { Recognized } \\
\text { perforations }\end{array}$ & $\begin{array}{c}\text { Unrecognized } \\
\text { perforations }\end{array}$ & $\begin{array}{c}\text { Marginal row } \\
\text { totals }\end{array}$ \\
\hline $\mathrm{Rx}$ & $12(14.5)[0.43]$ & $6(3.5)[1.79]$ & 18 \\
$\mathrm{CBCT}$ & $17(14.5)[0.43]$ & $1(3.5)[1.79]$ & 18 \\
$\begin{array}{l}\text { Marginal } \\
\text { column totals }\end{array}$ & 29 & 7 & 36 (Grand Total)
\end{tabular}

The Chi-square statistic is 4.4335 . The $p$ value is 0.03524 . This result is significant at $p<0.05$.

B

\begin{tabular}{lccc}
\hline & $\begin{array}{c}\text { Recognized } \\
\text { perforations }\end{array}$ & $\begin{array}{c}\text { Unrecognized } \\
\text { perforations }\end{array}$ & $\begin{array}{c}\text { Marginal row } \\
\text { totals }\end{array}$ \\
\hline $\mathrm{Rx}$ & $10(9.5)[0.03]$ & $0(0.5)[0.5]$ & 10 \\
$\mathrm{CBCT}$ & $9(9.5)[0.03]$ & $1(0.5)[0.5]$ & 10
\end{tabular}

$\begin{array}{llll}\text { Marginal } & 19 & 1 & 20 \text { (Grand total) }\end{array}$

The Chi-square statistic is 1.0526 . The $p$ value is 0.304902 . This result is not significant at $\mathrm{p}<0.05$.

C

\begin{tabular}{lccc}
\hline & $\begin{array}{c}\text { Recognized } \\
\text { ledges }\end{array}$ & $\begin{array}{c}\text { Unrecognized } \\
\text { ledges }\end{array}$ & $\begin{array}{c}\text { Marginal row } \\
\text { totals }\end{array}$ \\
\hline $\mathrm{Rx}$ & $10(11.5)[0.2]$ & $3(1.5)[1.5]$ & 13 \\
$\mathrm{CBCT}$ & $13(11.5)[0.2]$ & $0(1.5)[1.5]$ & 13
\end{tabular}

$\begin{array}{llll}\text { Marginal } & 23 & 3 & 26 \text { (Grand total) }\end{array}$

The Chi-square statistic is 3.3913. The $p$ value is 0.065541 . This result is not significant at $\mathrm{p}<0.05$.

D

\begin{tabular}{lccc}
\hline & $\begin{array}{c}\text { Recognized } \\
\text { accidents }\end{array}$ & $\begin{array}{c}\text { Unrecognized } \\
\text { accidents }\end{array}$ & $\begin{array}{c}\text { Marginal row } \\
\text { totals }\end{array}$ \\
\hline $\mathrm{Rx}$ & $32(35.5)[0.35]$ & $9(5.5)[2.23]$ & 41 \\
$\mathrm{CBCT}$ & $39(35.5)[0.35]$ & $2(5.5)[2.23]$ & 41
\end{tabular}

Marginal

71

11

82 (Grand total)

column totals

The Chi-square statistic is 5.1447. The $p$ value is 0.023318 . This result is significant at $\mathrm{p}<0.05$. their identification and the establishment of the further treatment plan are the keys to success.

Digital periapical radiographs are the most common imaging modalities used during endodontic treatments to establish the progression, outcome and the quality of the treatment. Although this technique has its own limitations- since it offers only a two-dimensional picture of the three-dimensional structures-, it is widely used because of its lower costs and easier evaluation possibilities.

The introduction of the CBCT changed the perspectives in some fields of dentistry, such as implantology and endodontics. The scanned images are capable to offer three-dimensional views of the explored structures $[7,8]$. This ability of the CBCT allows a better identification of the procedural accidents which occur during root canal treatments $[9,10]$. Perforations, broken instruments and ledge formations were easily detected on the scanned images by the evaluators. Higher cost and higher radiation are the only limitations of the CBCT $[11,12]$.

Some procedural accidents as coronal and external root perforations or the fractured instruments in the root canals can be easily detected on the digital periapical radiographs. For a better detection of the ledges or the interradicular perforations on digital radiographs it is recommended to insert radiopaque materials (gutta-percha cones or endodontic files) into the root canals before capturing the images [13]. Thesis and his colleagues in their paper also recommend this method for an easier identification of some procedural accidents [14] (Figure 2).

CBCT enhances the number of detection of interradicular perforations and ledge formations compared to the digital radiograph images. According to the international literature, Shokri et al obtained the same results [15]. Their conclusion was that CBCT scans are the best imaging method for the identification of root perforations (Figure 3).

According to international literature several studies demonstrated that CBCT has the highest accuracy among the imaging modalities to detect perforations and other procedural accidents which occur during root canal treatment $[6,15,16]$ Nevertheless, the digital intraoral periapical radiographs-with their limitations- still remain the most frequently used investigations during endodontic therapy. The images captured with this technique are almost as useful before, during and after the root canal treatment as the cone beam computer tomography scans $[13,14,17]$

A limitation of this study could be the fact that the accidents were artificially created and easily recognizable. In addition, the soft tissue simulation did not provide the same image quality as in clinical settings. These conditions and the lack of patient movement could lead to overestimation during evaluation.In clinical setting additional factors such as performance of the evaluators, patient related factors and software specifications of the digital radiographs and the CBCT can affect the diagnosis of the procedural accidents. 


\section{Conflicts of interest}

The authors report no conflicts of interest.

\section{References}

1. American Association of Endodontists. Glossary of endodontic terms, 7th ed. Chicago, III: American Association of Endodontists, 2003.

2. Shemesh $\mathrm{H}$, Cristescu RC, Wesselink PR, Wu MK. The use of cone-beam computed tomography and digital periapical radiographs to diagnose root perforation. J Endod.2011;37:513-516. doi: 10.1016/j.joen.2010.12.003

3. Shokri A, Eskandarloo A, Noruzi-Gangachin M, Khajeh S (2014) Detection of root perforations using conventional and digital intraoral radiography, multidetector computed tomography and cone beam computed tomography. Restor Dent Endod. 2015;40(1):58-67. doi:10.5395/ rde.2015.40.1.58

4. Alamri HM, Sadrameli M, Alshalhoob MA, Sadrameli M, Alshehri MA.Applications of CBCT in dental practice: a review of the literature. Gen Dent.2012;60:390-400

5. Bagis N, Kolsuz ME, Kursun S, OrhanK. Comparison of intraoral radiography and cone-beam computed tomography for the detection of periodontal defects: an in vitro study.BMC Oral Health2015;15:64. doi:10.1186/s12903-015-0046-2.

6. Cohenca N, ShemeshH. Clinical applications of cone beam computed tomography in endodontics: A comprehensive review.Quintessence Int. 2015;46(6):465-480. doi:10.3290/j.qi.a33990.

7. Bueno MR, Estrela C, De Figueiredo JA, Azevedo BC. Map-reading strategy to diagnose root perforations near metallic intracanal posts by using cone beam computed tomography. J Endod.2011;37(1):85-90. doi: 10.1016/j.joen.2010.08.006.

8. Khojastepour L, Moazami F, Babaei M, Forghani M. Assessment of Root Perforation within Simulated Internal Resorption Cavities Using Cone-beam Computed Tomography.J Endod. 2015;41(9):1520-1523. doi:10.1016/j.joen.2015.04.015.

9. Orlando Aguirre Guedes, Marcus Vinícius, et al. Detection of Procedural Errors during Root Canal Instrumentation using Cone Beam Computed Tomography. J Int Oral Health. 2015;7(3):28-32.

10. Patcas R, Angst C, Kellenberger CJ, Schätzle MA, Ullrich O, MarkicG. Method of visualisation influences accuracy of measurements in conebeam computed tomography.J Craniomaxillofac Surg. 2015;43(7):12771283. doi:10.1016/j.jcms.2015.05.001

11. Schulze R, Heil $U$, Gross D, et al.Artefacts in CBCT: a review. DentomaxillofacRadiol.2011;40:265-73. doi: 10.1259/ dmfr/30642039.

12. Kyung-San Min. Management of root canal perforation by using conebeam computed tomography.Restor Dent Endod. 2013;38(1):55-56. doi:10.5395/rde.2013.38.1.55

13. Kühl S, Zürcher S, Zitzmann NU, Filippi A, Payer M, Dagassan-Berndt D.Detection of peri-implant bone defects with different radiographic techniques - a human cadaver study.Clin Oral Implants Res. 2016;27(5):529-34. doi:10.1111/clr.12619.

14. Thesis Igor, Zvi Fuss. Diagnosis and treatment of accidental root perforations. Endodontic Topics. 2006;13(1):95-107.DOI:10.1111/ j.1601-1546.2006.00213.x

15. Kumar M, Shanavas M, Sidappa A, Kiran M.Cone beam computed tomography - know its secrets.J Int Oral Health. 2015;7(2):64-68.

16. Song CK, Chang HS, Min KS. Endodontic management of supernumerary tooth fused with maxillary first molar by using cone-beam computed tomography. J Endod. 2010;36:1901-1904.doi: 10.1016/j. joen.2010.08.026.

17. D’Addazio PS, Campos CN, Özcan M, Teixeira HG, PassoniRM, Carvalho AC. A comparative study between cone beam computed tomography and periapical radiographs in diagnosis of simulated endodontic complications. IntEndod J.2011:44:218-224. doi: 10.1111/j.13652591.2010.01802.x 